\title{
No more time to stay 'single' in the detection of Anisakis pegreffi, $A$. simplex (s. s.) and hybridization events between them: a multi-marker nuclear genotyping approach
}

\author{
S. MATTIUCCI ${ }^{1}$, V. ACERRA ${ }^{1,2}$, M. PAOLETTI ${ }^{1,2}$, P. CIPRIANI ${ }^{1,2}$, A. LEVSEN $^{3}$, \\ S. C. WEBB ${ }^{4}$, D. CANESTRELLI ${ }^{2}$ and G. NASCETTI ${ }^{2}$ \\ ${ }^{1}$ Department of Public Health and Infectious Diseases, Section of Parasitology, 'Sapienza -University of Rome', \\ P.le Aldo Moro, 500185 Rome, Italy \\ ${ }^{2}$ Department of Ecological and Biological Sciences, Tuscia University, Viale dell'Università s/n 01100 Viterbo, Italy \\ ${ }^{3}$ National Institute of Nutrition and Seafood Research (NIFES), Strandgaten 229, N-5004 Bergen, Norway \\ ${ }^{4}$ Cawthron Institute, Private Bag 2, Nelson 7042, New Zealand
}

(Received 22 October 2015; revised 22 Fanuary 2016; accepted 28 Fanuary 2016; first published online 5 April 2016)

\begin{abstract}
SUMMARY
A multi-marker nuclear genotyping approach was performed on larval and adult specimens of Anisakis spp. $(N=689)$ collected from fish and cetaceans in allopatric and sympatric areas of the two species Anisakis pegreffi and Anisakis simplex (s. s.), in order to: (1) identify specimens belonging to the parental taxa by using nuclear markers (allozymes loci) and sequence analysis of a new diagnostic nuclear DNA locus (i.e. partial sequence of the EF1 $\alpha-1 n$ DNA region) and (2) recognize hybrid categories. According to the Bayesian clustering algorithms, based on those markers, most of the individuals $(N=678)$ were identified as the parental species [i.e. A. pegreffi or $A$. simplex (s. s.)], whereas a smaller portion $(N=11)$ were recognized as $\mathrm{F}_{1}$ hybrids. Discordant results were obtained when using the polymerase chain reaction-restriction fragment length polymorphisms (PCR-RFLPs) of the internal transcribed spacer (ITS) ribosomal DNA (rDNA) on the same specimens, which indicated the occurrence of a large number of 'hybrids' both in sympatry and allopatry. These findings raise the question of possible misidentification of specimens belonging to the two parental Anisakis and their hybrid categories derived from the application of that single marker (i.e. PCR-RFLPs analysis of the ITS of rDNA). Finally, Bayesian clustering, using allozymes and EF1 $\alpha-1 n$ DNA markers, has demonstrated that hybridization between $A$.pegreffi and $A$. simplex (s. s.) is a contemporary phenomenon in sympatric areas, while no introgressive hybridization takes place between the two species.
\end{abstract}

Key words: Anisakis pegreffi, A. simplex (s. s.), multi-marker genotyping approach, elongation factor 1 alpha1 nDNA (EF1 $\alpha-1$ nDNA region), contemporary hybridization.

\section{INTRODUCTION}

Ecological and epidemiological studies require that actual parasite species can be accurately defined (Criscione et al. 2005). On the other hand, species delimitation, the process of identifying and delineating distinct taxonomic entities, remains among the most challenging tasks in the study of parasite biodiversity. Cryptic species of parasites may occur when one or more established characters (often morphology) for defining species limits are uninformative and/or incongruent (Pérez-Ponce de León and Nadler, 2010; Nadler and Pérez-Ponce de León, 2011). Thus, molecular methodologies provide a valuable source of additional markers in such cases of heterogeneity and fill the gap in delimiting populations and species of parasites. This also concerns the application of genetic markers in anisakid nematodes, demonstrating reproductive

* Corresponding author: Department of Public Health and Infectious Diseases, Section of Parasitology, Sapienza-University of Rome, P.le Aldo Moro, 500185 Rome, Italy. E-mail: simonetta.mattiucci@uniroma1.it isolation in sympatry and allopatry, and in giving estimates of gene flow between them (Mattiucci and Nascetti, 2008). In other words, molecular markers, particularly nuclear ones, provide evidence for the existence of biological species (BSC, sensu Mayr and Ashlock, 1969). Despite the fact that in recent years the BSC concept has been supported by the Phylogenetic species concept (PSC, sensu Avise and Wollenberg, 1997), under which "a species has been defined as a monophyletic group composed of a cluster of individual organisms within which there is a parental pattern of ancestry and descent", it has been suggested how principles of 'genealogies concordance' might be employed to combine elements of the PSC and the BSC (Avise and Wollenberg, 1997). Furthermore, rather than concentrating on a single character type (e.g. morphological or DNA sequence variation), a wide range of characters (including not only molecular/ genetic data but also morphology, ecology, geography, pathogenicity, host specificity/host range, etc.) are integral to delimiting parasite species and assessing species boundaries. 
It has been frequently reported that sympatric populations of closely related parasite species might interbreed (Agatsuma et al. 2000; Steinauer et al. 2008; Detwiler and Criscione, 2010), including parasitic nematodes (Anderson, 2001; Criscione et al. 2007; Dunams-Morel et al. 2012). Hybridization, through interspecific crossing between closely related species, could have major evolutionary consequences for species and populations by either promoting or preventing divergence, depending by the viability and reproductive abilities of the hybrids in producing backcrosses with parental species. Adaptive traits could be also acquired through hybridization, resulting in increased or lower fitness in hybrid individuals (Criscione et al. 2007; Gilabert and Wasmuth, 2013). Hybridization and introgression could lead to some phenotypic changes of pathogens, including parasites, such as the invasion of new hosts, new geographical areas and site of infection (Criscione et al. 2007; Detwiler and Criscione, 2010). Therefore, the accurate detection and characterization of hybridization is important both in basic and applied biology, and not only in free-living species but also in parasitic animals. Again, molecular/genetic markers, especially the nuclear ones, are making these analyses accessible via a large number of tested individuals.

However, hybridization, introgression and the retention of ancestral polymorphism in closely related parasitic taxa could generate patterns of genetic variation which complicate their disclosure, when choosing inappropriate genetic/molecular markers and/or when the detection of hybridization is inferred by genetic markers obtained from the analysis of a single locus. A common approach to identifying hybrids is the use of parental taxa specific diagnostic markers at nuclear loci, such as allozymes, which are fixed in the parental species over a large sample size from various hosts and geographical areas; mixed (heterozygote) banding patterns of offspring individuals, indicating natural hybridization can be detected. Discordance between nuclear and mitochondrial datasets has also been used to distinguish putative hybrids between closely related species (Okamoto et al. 2010). The availability of highly polymorphic genetic markers and Bayesian clustering methods, such as STRUCTURE (Pritchard et al. 2000) and NEWHYBRIDS (Anderson and Thompson, 2002), has also improved our knowledge of hybridization events in parasitic nematodes (Criscione et al. 2007; Gilabert and Wasmuth, 2013).

The two cryptic species, Anisakis simplex (s. s.) and Anisakis pegreffii, were first detected according to the BSC rule by multiple allozyme loci, which provided evidence for their reproductive isolation and the apparent absence of gene flow between them (Nascetti et al. 1986; Mattiucci et al. 2014). Later, they were depicted as distinct phylogenetic lineages (according to the PSC rule), as inferred from concatenated sequence analyses of both mitochondrial and nuclear DNA loci (Valentini et al. 2006; Mattiucci et al. 2014) and by the Procruster Rotation Analysis (PR), combining molecular/ genetic datasets with morphological/morphometric traits of adult specimens of the two Anisakis species (Mattiucci et al. 2014). The two species were also found to differ in their geographical distribution (Nascetti et al. 1986; Mattiucci et al. 1997, 2014); however, their ranges overlap in some oceanic basins, such as the NE Atlantic Ocean (Spanish-Portuguese coast) and the Western Pacific Ocean (East China Sea and Sea of Japan) (Mattiucci et al. 1997, 2014; Abollo et al. 2001; Pontes et al. 2005; Mattiucci and Nascetti, 2008; Lee et al. 2009; Suzuki et al. 2010; Chou et al. 2011; Quiazon et al. 2011). In those areas, co-infection by Anisakis species pairs can occur in both pelagic and demersal fish hosts as well as in oceanic dolphin species (Mattiucci et al. 1997, 2004, 2008, 2014; Abollo et al. 2001; Pontes et al. 2005; Farjallah et al. 2008; Mattiucci and Nascetti, 2008). The occurrence of specimens, sometimes indicated as 'putative hybrids', or 'recombinant genotypes' or just 'hybrids', between the two species $A$. simplex (s. s.) and $A$. pegreffi $i$ has been reported by using polymerase chain reaction - restriction fragment length polymorphisms (PCR-RFLPs) of the internal transcribed spacer (ITS) region of ribosomal DNA (rDNA) and sequence analysis of the same gene. These specimens were either larval stages collected from various fish species or adults from cetaceans, from both allopatric (such as the Mediterranean Sea) (Farjallah et al. 2008; Meloni et al. 2011; Chaligiannis et al. 2012; Cavallero et al. 2012, 2014; Pekmezci et al. 2014) and sympatric areas (Abollo et al. 2003; Martìn-Sànchez et al. 2005; Umehara et al. 2006; Lee et al. 2009; Suzuki et al. 2010; Chou et al. 2011; Quiazon et al. 2011; Molina-Fernández et al. 2015).

Unfortunately, the above studies used a single nuclear marker (the ITS region of rDNA) and, consequently, lacked the power to decipher whether or not the observed shared polymorphism between the two taxa was caused by incomplete lineage sorting, historical introgression or current hybridization. As a result, whether A. simplex (s. s.) and $A$. pegreffi can hybridize remained an open question.

In the present paper, a Bayesian clustering of genotypes obtained from multi-marker nuclear loci analysis of individual nematodes of Anisakis spp. collected from allopatric and sympatric areas of the two species [A. pegreffi $i$ and $A$. simplex (s. s.)] was carried out in order to: (1) correctly identify specimens belonging to the parental taxa $[A$. pegreffi and $A$. simplex (s. s.)]; (2) compare the assignment of each Anisakis specimen obtained by biparentally inherited codominant nuclear markers (allozyme 
loci) and the sequence analysis of a new nuclear DNA locus (i.e. partial sequence of the elongation factor 1 alpha1 gene) with respect to the assignment obtained, on the same specimens, by means of the single molecular marker extensively used to distinguish the two species (i.e. the analysis of ITS region of rDNA); (3) recognize hybrid categories between the two taxa; and (4) distinguish introgression or current hybridization phenomena between the two species.

\section{MATERIALS AND METHODS}

\section{Sampling}

A total of 689 specimens of Anisakis spp. were examined. They were collected as the L3 larval stage from intermediate/paratenic fish hosts and as adults from cetacean species in sampling localities of the NE Atlantic Ocean, Mediterranean Sea and SW Pacific Ocean (Fig. 1, and Table 1). These localities are included in the geographical ranges of two species A. pegreffii and A. simplex (s. s.), from where they are reported both as allopatric [i.e. the North Sea for A. simplex (s. s.) and the South West Pacific Ocean for the species $A$. pegreffic or as sympatric (i.e. the NE Atlantic Ocean off the coast of Portugal and Spain, Alboran Sea), according to Mattiucci et al. (1997, 2004, 2008, 2014), Abollo et al. (2001), Mattiucci and Nascetti (2008), Levsen and Lunestad (2010), Levsen and Karl (2014). Details concerning the sampling localities of the intermediate/paratenic (fish) and definitive hosts (cetaceans) of the two Anisakis species examined in this study are given in Table 1. Some of the nematodes were obtained from the frozen collection of anisakids stored in the Section of Parasitology, Department of Public Health and Infectious Diseases of 'Sapienza University in Rome', whereas new samples were collected during the years 2013-2014 from fish in the framework of the Project PARASITE and belong to the PARASITE-Biobank Node at the Section of Parasitology (Sapienza-University). In addition, the collection of adults was undertaken during the years 20112012 from stranded cetaceans, i.e. the pilot whale, Globicephala melas Traill, in the Southern Pacific Ocean (off the coast of New Zealand) and the striped dolphin, Stenella coeruleoalba (Meyen), stranded off the Italian coast. Nematodes collected from the stomach of their hosts were repeatedly washed in saline solution and preserved by freezing at $-70^{\circ} \mathrm{C}$ in distilled water or stored in $70 \%$ alcohol.

\section{Laboratory procedures}

Individual multi-locus genotypes of the 689 sampled individuals of Anisakis spp. were obtained by using 3 distinct classes of molecular markers: allozymes, sequence analysis of the elongation factor EF1 $\alpha-1$ nuclear DNA gene and RFLP analysis of the ITS rDNA region (as well as sequences analysis of the same gene).

Standard horizontal starch gel electrophoresis was performed to analyse variation at 4 allozyme loci of diagnostic value for the studied species (Mattiucci et al. 1997, 2014). These loci were: adenylate kinase $(A d k-2$, EC $2 \cdot 7 \cdot 4 \cdot 3)$, leucine-alanine peptidase (Pep $C$-1, $P e p C$-2, EC 3.4.11) and superoxide dismutase $(S o d-1$, EC $1 \cdot 15 \cdot 1 \cdot 1)$. The procedures of starch gel electrophoresis used in this study were described in detail by Mattiucci et al. (1997).

Tissue homogenates, obtained during the starch gel electrophoresis procedures, were preserved at $-20{ }^{\circ} \mathrm{C}$ and subsequently used to obtain genomic DNA extracts of each examined individual. The total DNA was extracted using the cetyltrithylammonium bromide method, as detailed elsewhere (Mattiucci et al. 2014). DNA obtained was quantified by using the Qubit ${ }^{\mathrm{TM}}$ dsDNA HS Assay Kit with Qubit 2·0 (Invitrogen ${ }^{\mathrm{TM}}$ ).

For sequencing the ITS rDNA region, PCR amplification was performed using the primers NC5 (5'-GTAGGTGAACCTGCGGAAGGATC ATT-3') and NC2 (5'-TTAGTTTC'TTTTCCT CCGCT-3') according to the procedure reported in Zhu et al . (2000) and Abollo et al. (2003). PCR amplification conditions were the following: $95^{\circ} \mathrm{C}$ for $10 \mathrm{~min}$ (initial denaturation), followed by 30 cycles at $95^{\circ} \mathrm{C}$ for $30 \mathrm{~s}$ (denaturation), $55^{\circ} \mathrm{C}$ for $30 \mathrm{~s}$ (annealing), $72^{\circ} \mathrm{C}$ for $75 \mathrm{~s}$ (extension) and a final elongation step at $72{ }^{\circ} \mathrm{C}$ for $7 \mathrm{~min}$. Three $\mu \mathrm{L}$ of the amplification products were visualised on $1 \%$ Gel-Red (Biotium) stained agarose gels to check the quality of amplification. PCR products were then digested using the HinfI restriction endonuclease according to the standard procedures (D'Amelio et al. 2000; Abollo et al. 2003; Pontes et al. 2005). The digestion was performed using $1 \mu \mathrm{L}$ of restriction enzymes (Hinf I), $1 \mu \mathrm{L}$ of BSA (Bovine Serum Albumin, Acetylated, $10 \mathrm{mg} \mathrm{mL}^{-1}$ ), $1 \mu \mathrm{L}$ of buffer B $10 \times$ and $7 \mu \mathrm{L}$ of PCR products up to a final volume of $10 \mu \mathrm{L}$. The digestion was performed for $3 \mathrm{~h}$ at $37^{\circ} \mathrm{C}$. Restriction patterns were visualized on $3 \%$ agarose gels under UV-light. Further confirmation of the heterozygote restriction patterns produced by digestion with HinfI for some individuals was obtained by sequencing the ITS rDNA using those PCR primers.

For the elongation factor (EF1 $\alpha-1$ nDNA) nuclear gene, oligonucleotide primers were designed based on the elongation factor 1 alpha1 gene of genomic DNA sequence deposited in the GenBank database under the accession number KP326558. The primers used in the present paper were designed by hand and verified by means of the on-line software program Primer3 (http://bioinfo.ut.ee/ primer3-0.4.0/). Thus, PCR amplification was performed using the primers EF-F (5'-TCCTCAA 


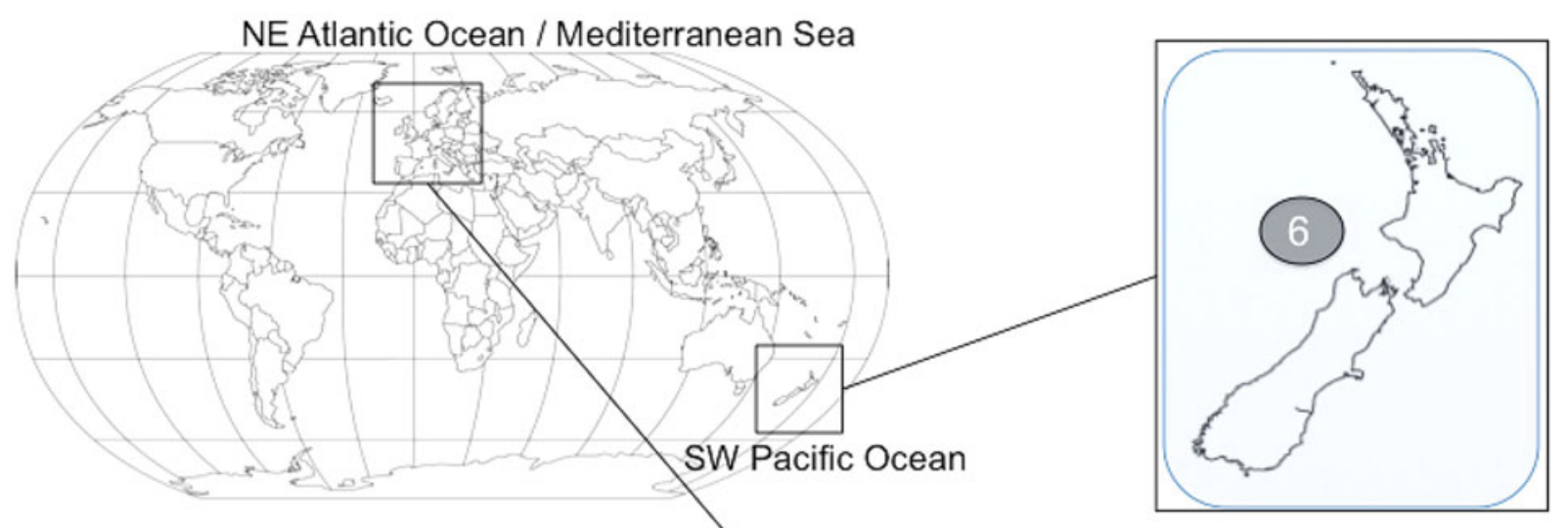

1. North Sea

2. Spanish-Portuguese Coast

3. Alboran Sea

4. Tyrrhenian Sea

5. Adriatic Sea

6. New Zealand Coast

\section{A. pegreffii}

A. simplex (s. s.)

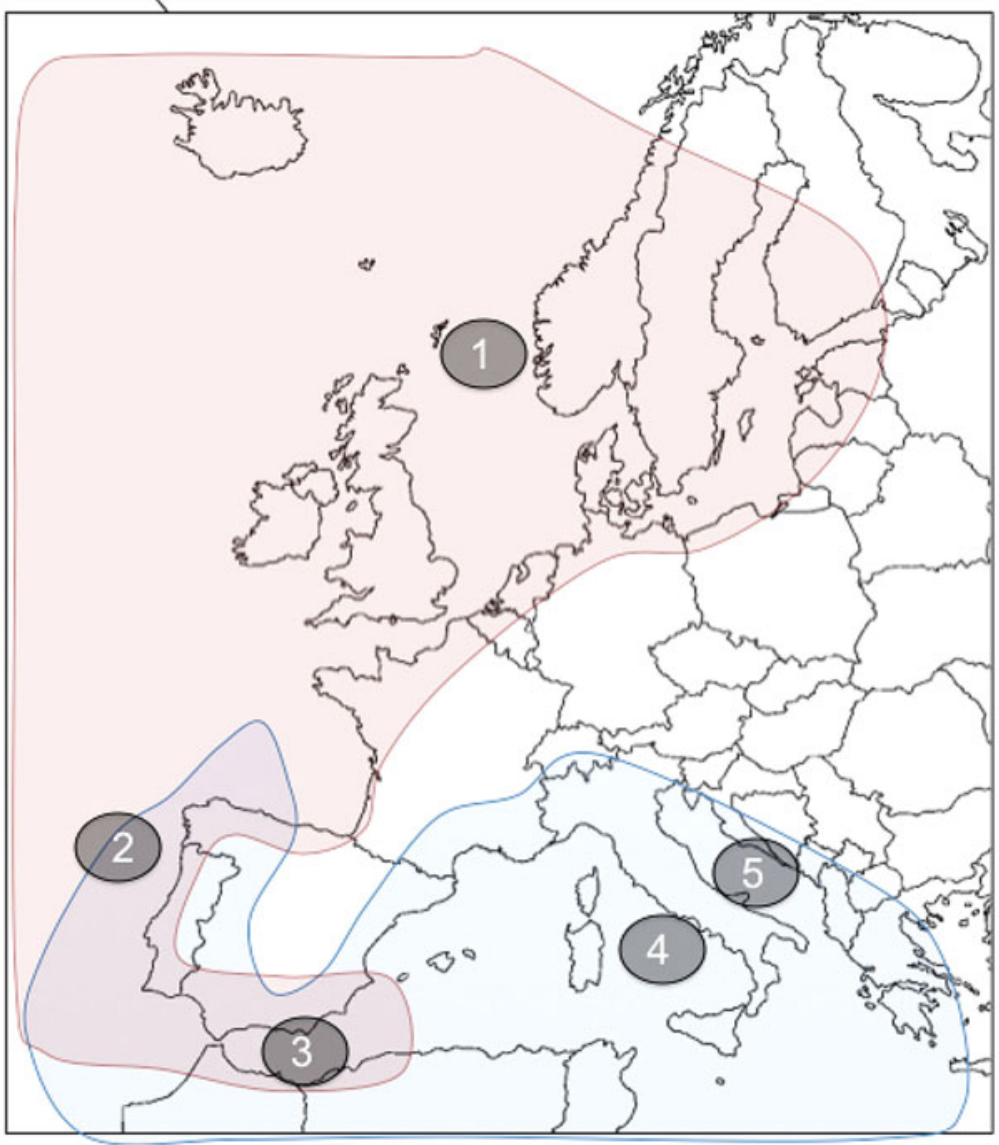

Fig. 1. Map of the geographical areas from where the sampling of larvae and adults of $A$. simplex (s. s.) and $A$.pegreffi (as referred to in Table 1) was carried out.

GCGTTGTTATCTGTT-3') and EF-R (5'-AG TTTTGCCACTAGCGGTTCC-3'). PCRs were carried out in a $25 \mu \mathrm{L}$ volume containing $0 \cdot 5 \mu \mathrm{L}$ of each primer $10 \mathrm{mM}, \quad 2 \cdot 5 \mu \mathrm{L}$ of $\mathrm{MgCl}_{2} 25 \mathrm{~mm}$ (Promega), $1 \cdot 5 \mu \mathrm{L}$ of $5 \times$ buffer (Promega), DMSO $0 \cdot 08 \mathrm{~mm}, 0 \cdot 5 \mu \mathrm{L}$ of dNTPs $10 \mathrm{~mm}$ (Promega), $5 \mathrm{U}$ of Go-Taq Polymerase (Promega) and $2 \mu \mathrm{L}$ of total DNA. PCR temperature conditions were the following: $94^{\circ} \mathrm{C}$ for $3 \mathrm{~min}$ (initial denaturation), followed by 35 cycles at $94^{\circ} \mathrm{C}$ for $45 \mathrm{~s}$ (denaturation), $58^{\circ} \mathrm{C}$ for $40 \mathrm{~s}$ (annealing), $72^{\circ} \mathrm{C}$ for $1 \mathrm{~min}$ (extension) and followed by post-amplification at $72^{\circ} \mathrm{C}$ for $10 \mathrm{~min}$. An initial sample of 50 individuals, belonging to the two species, $A$. pegreffii and $A$. simplex (s. s.), previously identified by allozymes, were sequenced at the elongation factor 1 alpha1 gene. The sequences obtained were aligned in order to detect fixed diagnostic nucleotide positions able to discriminate the two species under study. Then, all the specimens analysed in the present paper were sequenced at the EF1 $\alpha-1 \mathrm{nDNA}$ gene.

\section{Data analysis}

The sequences obtained from ITS rDNA and EF1 $\alpha-1$ nDNA region were aligned by using Clustal $\mathrm{X}$ version 2.0 software (Larkin et al. 2007). ITS rDNA sequences were also analysed by Genbank 
Table 1. Sampling area, host species and life-history stage of the specimens studied from allopatric and sympatric areas of the nematodes Anisakis pegreffii and A. simplex (s. s.)

\begin{tabular}{|c|c|c|c|}
\hline Sampling area & Host species & $N$ & $\begin{array}{l}\text { Life-history } \\
\text { stage }\end{array}$ \\
\hline \multicolumn{4}{|l|}{ NE Atlantic Ocean } \\
\hline \multirow[t]{3}{*}{ 1. North Sea $\left(59^{\circ} 13^{\prime} \mathrm{N}-00^{\circ} 14^{\prime} \mathrm{W}\right)$} & Clupea harengus & 8 & L3 \\
\hline & Micromesistius poutassou & 28 & L3 \\
\hline & Scomber scombrus & 68 & L3 \\
\hline $\begin{array}{l}\text { 2. Spanish-Portuguese Atlantic coast } \\
\left(41^{\circ} 48^{\prime} \mathrm{N}-9^{\circ} 44^{\prime} \mathrm{W}\right)\end{array}$ & Merluccius merluccius & 157 & L3 \\
\hline \multicolumn{4}{|l|}{ Mediterranean Sea } \\
\hline \multirow[t]{3}{*}{ 3. Alboran Sea $\left(36^{\circ} 31^{\prime} \mathrm{N}-3^{\circ} 26^{\prime} \mathrm{W}\right)$} & Lophius piscatorius & 9 & L3 \\
\hline & Scomber scombrus & 5 & L3 \\
\hline & Merluccius merluccius & 10 & L3 \\
\hline \multirow[t]{3}{*}{ 4. Tyrrhenian Sea $\left(41^{\circ} 7^{\prime} \mathrm{N}-13^{\circ} 24^{\prime} \mathrm{E}\right)$} & Lepidopus caudatus & 23 & L3 \\
\hline & Merluccius merluccius & 29 & L3 \\
\hline & Scomber scombrus & 19 & L3 \\
\hline \multirow[t]{6}{*}{ 5. Western Adriatic Sea $\left(42^{\circ} 18^{\prime} \mathrm{N}-15^{\circ} 35^{\prime} \mathrm{E}\right)$} & Stenella coeruleoalba & 137 & A \\
\hline & Engraulis encrasicolus & 3 & L3 \\
\hline & Lophius piscatorius & 5 & L3 \\
\hline & Merluccius merluccius & 18 & L3 \\
\hline & Trachurus trachurus & 26 & L3 \\
\hline & Scomber scombrus & 35 & L3 \\
\hline \multicolumn{4}{|l|}{ SW Pacific Ocean } \\
\hline 6. New Zealand coast $\left(44^{\circ} 30^{\prime} \mathrm{S}-172^{\circ} 58^{\prime} \mathrm{E}\right)$ & Globicephala melas & 109 & A \\
\hline
\end{tabular}

$\mathrm{A}=$ adult; $\mathrm{L} 3=3^{\text {rd }}$ stage larvae; $N=$ number of parasites analysed by: allozymes, sequence analysis of the EF1 $\alpha-1 n \mathrm{DNA}$ partial gene, and PCR-RFLPs of the ITS rDNA region.

Blast software, in order to verify their similarity with respect to the species under study, and aligned with those from the same species previously obtained (Mattiucci et al. 2014) by using Clustal X 2.0 (Larkin et al. 2007).

All subsequent population genetic analyses were carried out on individual multi-locus genotypes based on the four allozyme loci, and the pattern of variation at diagnostic nucleotide positions of the EF1 $\alpha-1 n$ DNA region (i.e. 5 distinct loci overall). The occurrences of the expected Hardy-Weinberg equilibrium for each locus and the genotypic linkage equilibrium between each pair of loci were assessed by means of exact tests, as implemented in the software GENEPOP (web version; Rousset, 2008). Significance levels were adjusted using the sequential Bonferroni correction for multiple tests (Rice, 1989). To investigate the population genetic structure in our dataset inferred from those five distinct loci (allozymes and EF1 $\alpha-1 \mathrm{nDNA}$ region) and to identify instances of gene exchange between species, a Bayesian clustering algorithm was used by means of the program STRUCTURE $2 \cdot 3 \cdot 3$ (Pritchard et al. 2000). STRUCTURE is a modelbased procedure that uses individual multi-locus genotypes to identify the optimal number of clusters $(K)$ in a dataset, by minimizing the resulting HardyWeinberg and linkage disequilibria. The analysis was run setting the predefined number of clusters between 1 and 6 (i.e. the number of sampling areas in our dataset). Ten replicates of the analysis were carried out to check for consistency, each run for 100000 MCMC iterations, following a burn-in of 50000 iterations, under the admixture model and the assumption of correlated allele frequencies among populations. The best $K$ value was identified using both the $\log$ probability of the data and the rate of change in the log probability of the data between successive $K$ values as optimality criteria (Evanno et al. 2005).

The results obtained with the Bayesian clustering algorithm on those loci were compared with the results inferred from the single-locus approach based on the conventional PCR-RFLPs analysis of the single ITS rDNA marker in order to check for consistency. However, the genotypes inferred from PCR-RFLPs analysis of ITS rDNA were not included in the analysis of STRUCTURE, because the ITS region of rDNA undergoes concerted evolution (Elder and Turner, 1995; Ganley and Kobayashi, 2007), a phenomenon which violates the assumption of Hardy-Weinberg, necessary to perform elaboration by STRUCTURE.

\section{RESULTS}

\section{Allozyme markers}

According to the alleles observed at the diagnostic loci, i.e. Adk-2 $2^{100}$, Pep $C-1^{100}, P e p C-2^{100}$ (Fig. 2a) and $\operatorname{Sod}-1^{100}, 487$ specimens were assigned to the species $A$. pegreffi; whereas, according to the diagnostic alleles $A d k-2^{105}$, Pep $C-1^{90}$, Pep $C-2^{96}$ and 


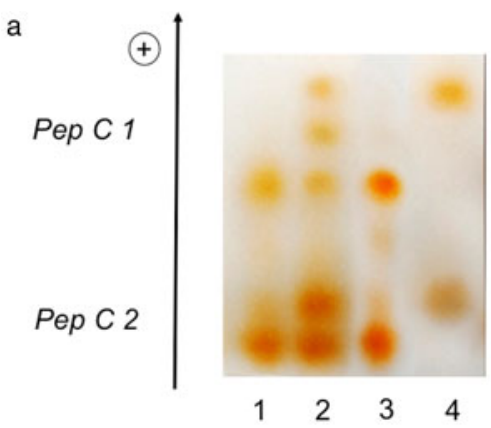

b

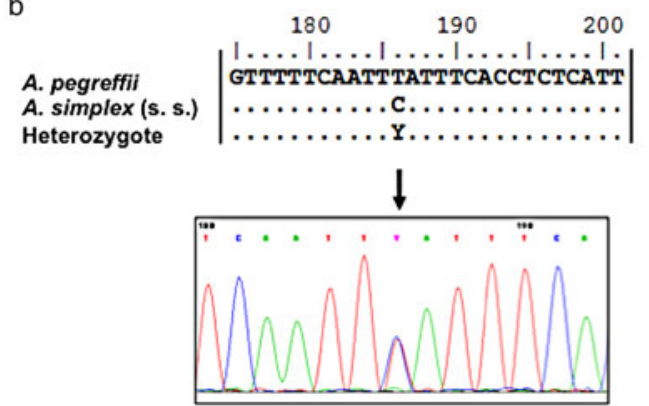

C

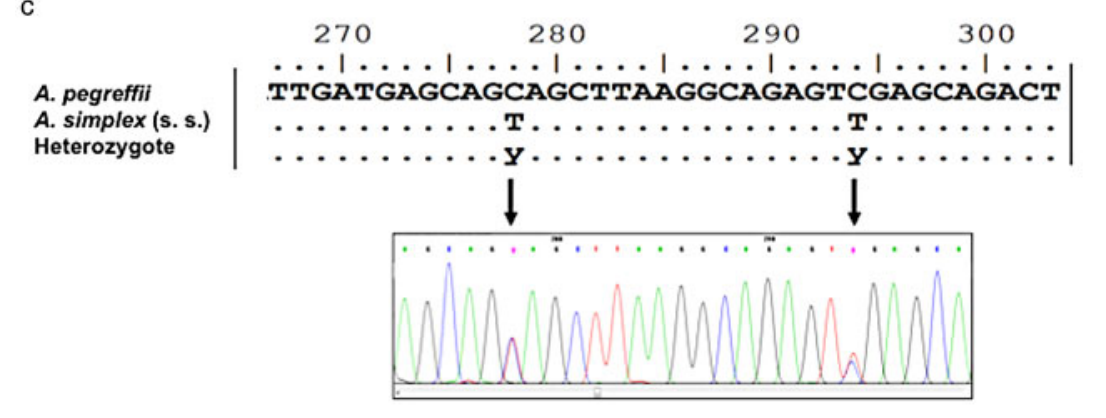

d

$\begin{array}{llllllllllllllllllll}1 & 2 & 3 & 4 & 5 & 6 & 7 & 8 & 9 & 10 & 11 & 12 & 13 & 14 & 15 & 16 & 17 & 18 & 19 & \mathrm{~L}\end{array}$
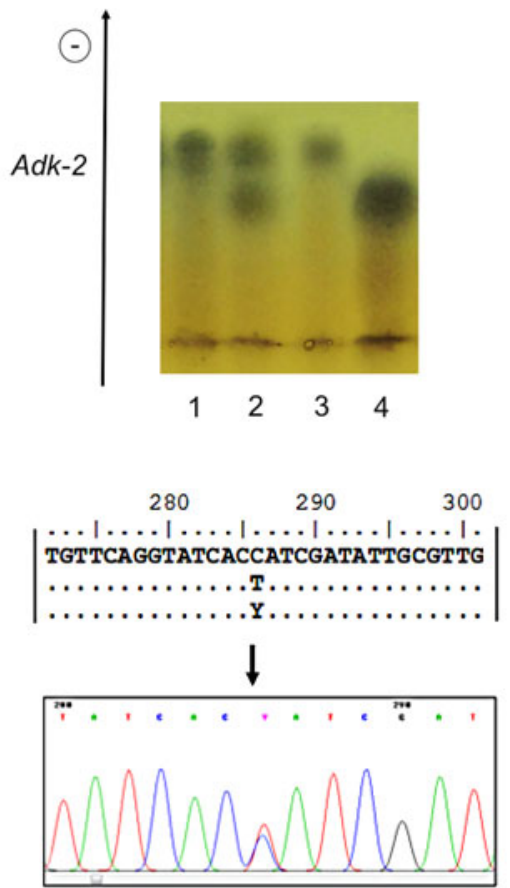

290

300

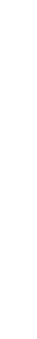

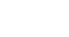

.

.
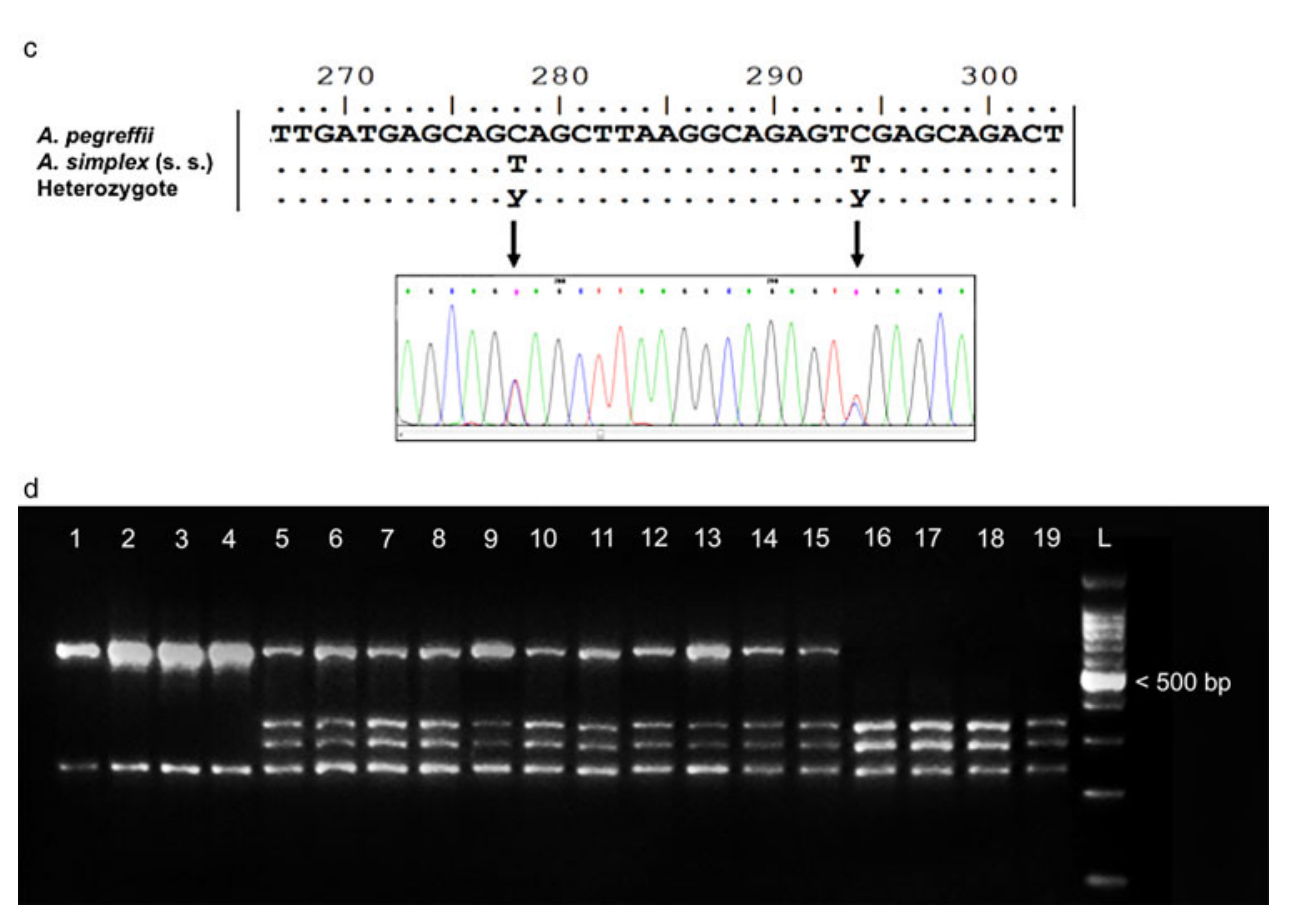

Fig. 2. Genotypes at each single nuclear genetic marker used in the present study. (a) Allozyme patterns obtained using enzymes $P e p C-1, P e p C-2$ and $A d k-2$; plate 1: Pep $C-1$ (dimeric structure, two alleles); specimen nos. 1 and 3: $A$. simplex (s. s.) homozygote pattern 90/90; specimen no. 4: A. pegreffi homozygote pattern 100/100; specimen no. 2: heterozygote pattern 90/100; Pep C-2 (monomeric structure, two alleles); specimen nos. 1 and 3: A. simplex (s. s.) homozygote pattern 96/96; specimen no. 4: A. pegreffii pattern 100/100; specimen no. 2: heterozygote pattern 96/100; plate 2: Adk-2

(monomeric structure, two alleles); specimen nos. 1 and 3: A. simplex (s. s.) homozygote pattern 105/105; specimen no. 4: A. pegreffi homozygote pattern 100/100; specimen no. 2: heterozygote pattern 100/105. (b) Alignment of the elongation factor (EF1 $\alpha-1 n \mathrm{DNA}$ ) nuclear gene in the two species $A$. pegreffi and $A$. simplex (s. s.). The arrows show the fixed diagnostic nucleotide positions detected between the two species. A heterozygote pattern at both positions is shown. The relative electropherogram of this genotype is also reported below. Dots indicate identity; standard IUPAC codes were used, i.e. $\mathrm{Y}=\mathrm{C} / \mathrm{T}$; (c) PCR-RFLP patterns obtained by digestion of the ITS region of rDNA with the restriction enzyme Hinf I (according to D'Amelio et al. 2000) showing: specimens nos. 1-4: A. simplex (s. s.) genotype (two bands); specimen nos. 16-19: A.pegreffi genotype (three bands); specimen nos. 5-15 heterozygote genotypes (four bands); L: 100 bp ladder. (d) Alignment of the ITS-1 region of rDNA and electropherogram of the same gene indicated by arrows, representing the two diagnostic positions (according to D'Amelio et al. 2000; Abollo et al. 2003) between the two species. The electropherogram of the heterozygote genotype is also shown below. Dots indicate identity; standard IUPAC codes are used, i.e. $\mathrm{Y}=\mathrm{C} / \mathrm{T}$. 
Sod-1 $1^{105}$ (Fig. 2a), as indicated in Mattiucci et al. (2014), 191 larvae corresponded to the species $A$. simplex (s. s.) (Table 2). Eleven larval specimens, collected in fish from the Spanish Atlantic coast $(N=10)$ and in a sample from the Alboran Sea $(N$ =1), showed a heterozygote genotype between $A$. pegreffii and $A$. simplex (s. s.) (Fig. 2a) at all the diagnostic allozyme loci (i.e. $A d k-2^{100 / 105}, P e p C-1^{90 / 100}$, $P e p C-2^{96 / 100}$ and $S o d-1^{100 / 105}$ ) (Table 2, Fig. 2a).

\section{Elongation factor 1 alpha1 nDNA subunit partial gene region}

A fragment of $409 \mathrm{bp}$ in length of the EF1 $\alpha-1$ nDNA region was obtained for all of the 689 specimens analysed. It revealed the presence of two diagnostic nucleotide sites between $A$. pegreffi and $A$. simplex (s. s.) (Fig. 2b). These positions were: 186, showing a $\mathrm{T}$ in $A$. pegreffii, whereas it was $\mathrm{C}$ in the parental taxon $A$. simplex (s. s.); and the position 286, showed a $\mathrm{C}$ in $A$. pegreffi but always a $\mathrm{T}$ in A. simplex (s. s.) (Fig. 2b).

According to the diagnostic positions detected, 487 specimens were assigned to the species $A$. pegreffi, whereas 191 were assigned to $A$. simplex (s. s.) (Table 2). In addition, 11 specimens showed a heterozygote genotype $(\mathrm{C} / \mathrm{T})$ at both diagnostic positions, i.e. 186 and 286, showing two overlapping $\mathrm{C} / \mathrm{T}$ peaks in the sequences analysed (Fig. $2 \mathrm{~b}$ ).

Sequences of the EF1 $\alpha-1$ nDNA region were deposited in GenBank under the accession numbers KT825684 for $A$. pegreffi, and KT825685 for A. simplex (s. s.).

\section{PCR-RFLPs of ITS region of $r D N A$}

The entire ITS1-5.8S-ITS2 rDNA region was amplified and a fragment of $905 \mathrm{bp}$ obtained from the same 689 Anisakis spp. individuals analysed at both diagnostic allozymes and the EF $1 \alpha-1 n$ DNA genes. Restriction with $\operatorname{HinfI}$ produced bands at 370,300 and $250 \mathrm{bp}$, corresponding to A. pegreffii in 469 specimens (Table 2, Fig. 2c), whereas fragments of 250 and $620 \mathrm{bp}$ in 190 specimens were found to belong to A. simplex (s. s.) (Table 2, Fig. 2c). Thirty Anisakis specimens exhibited a different restriction pattern using PCR-RFLP analysis. Here, the restriction with Hinf $\mathrm{I}$ digestion produced fragments of $620,370,300$ and $250 \mathrm{bp}$ that were heterozygote genotypes between $A$. pegreffii and $A$. simplex (s. s.) (Fig. 2c). The results achieved using the PCR-RFLPs of rDNA were confirmed by the aligned sequences at the ITS region of all the 689 specimens analysed (Fig. 2c). The sequences obtained matched the sequences previously deposited in GenBank for A. pegreffii or A. simplex (s. s.). Thus, following that putative diagnostic marker, 190 individuals (in fish hosts from the

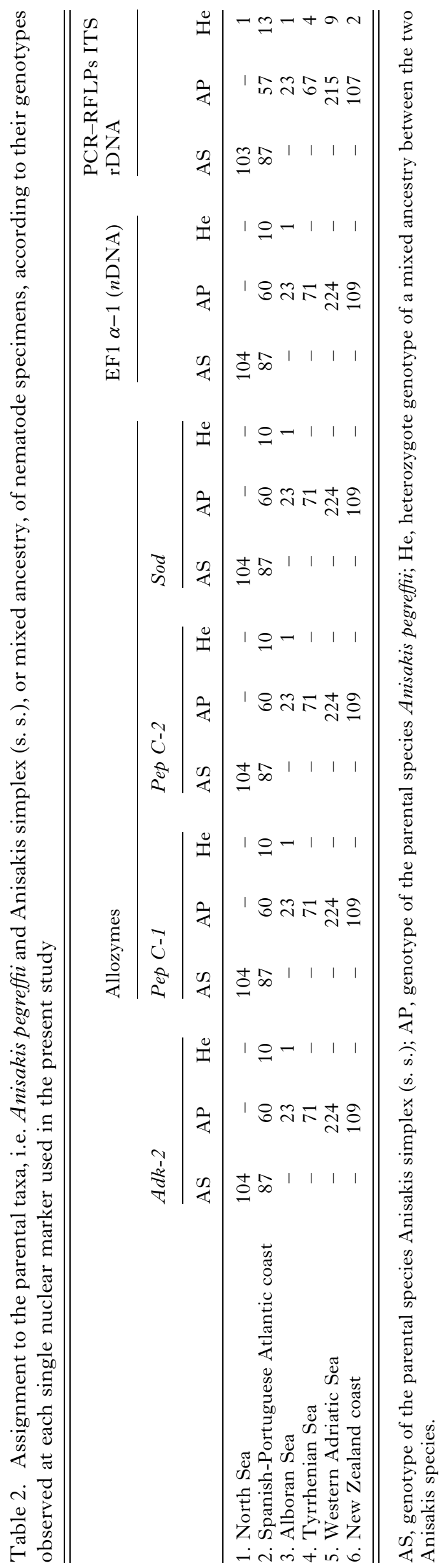




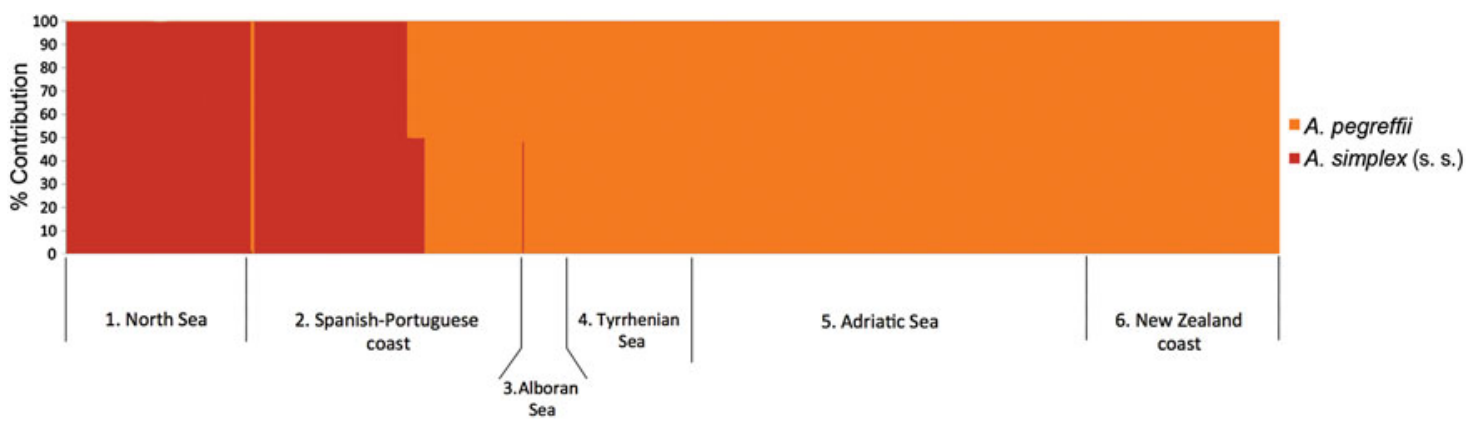

Fig. 3. Percentage contribution (Q value) of Anisakis pegreffii and A. simplex (s. s.) to the multi-locus genotype of each studied individual (barplots) estimated using STRUCTURE (a) with $k=2$. The numbers refer to the sampling areas (see Fig. 1 and Table 1), as follows: 1: North Sea; 2: Spanish-Portuguese Atlantic coast; 3: Alboran Sea; 4: Tyrrhenian Sea; 5: Adriatic Sea; 6: New Zealand coast.

North Sea and off the Spanish-Portuguese coast) matched the sequence corresponding to the species A. simplex (s. s.), whereas 469 specimens corresponded to $A$. pegreffii.

Finally, 30 individuals, characterized by the presence of two overlapping $\mathrm{C} / \mathrm{T}$ peaks in those diagnostic nucleotide positions (i.e. 278 and 294 of the ITS1 region of rDNA), confirmed a pattern of heterozygote genotypes (Fig. 2d). They included Anisakis specimens from two sympatric areas of the two species (i.e. the Spanish Atlantic coast and the Alboran Sea) (Fig. 1, Table 2). Thirteen heterozygote individuals were also recognized in the samples collected from the Mediterranean Sea, i.e. in areas nos. 4 and 5; and also in specimens collected in extreme allopatric areas (sample no. 1, North Sea; and no. 6, New Zealand) (Table 2 and Fig. 1).

However, among those 30 individuals showing the heterozygote pattern using the PCR-RFLPs of rDNA (Fig. 2d), only 11 individuals presented a heterozygote genotype at the other nuclear diagnostic loci (i.e. Adk-2, Pep C-1, Pep C-2, Sod and EF1 $\alpha-1$ nDNA region) (Table 2).

\section{Multi-marker genotyping data analysis by STRUCTURE}

Considering the discordance in the species assignments [i.e. to $A$. pegreffii or $A$. simplex (s. s.)] or heterozygote patterns obtained by the five nuclear loci (Adk-2, Pep C-1, Pep C-2, Sod-1 and EF1 $\alpha-1$ $n$ DNA) studied with respect to those obtained by PCR-RFLPs of rDNA of the ITS (Table 2), all the genotypes obtained at those five loci $(A d k-2$, Pep $C-1$, Pep $C-2$, Sod-1 and EF1 $\alpha-1$ nDNA) were tested for the occurrence of the expected Hardy-Weinberg equilibrium for each locus and the genotypic linkage equilibrium between each pair of loci. Strongly significant deviations from the expected Hardy-Weinberg equilibrium $(P<$ $0.0001)$ were observed for all the studied loci within the sample from area no. 2 (off the SpanishPortuguese Atlantic coast), whereas none of the other samples showed deviations. Similarly, the sample collected from off the Spanish-Portuguese Atlantic coast (no. 2) was the only one where significant linkage disequilibria were found among all pairs of loci (all $P<0 \cdot 0001$ ); in contrast, no statistically significant disequilibrium was observed within the other Anisakis samples.

The population genetic structure in our dataset and instances of gene exchange between $A$. pegreffi $i$ and $A$. simplex (s. s.) were then assessed on the basis of a Bayesian clustering algorithm implemented in the program STRUCTURE 2.3.3 (Pritchard et al. 2000). Using both the highest lnprobability and the delta- $K$ (Evanno et al. 2005) optimality criteria, the STRUCTURE analysis indicated $K=2$ as the clustering option which best fitted the data (see Supplementary Fig. 1). Considering the five diagnostic nuclear loci here studied (Adk-2, Pep C-1, Pep C-2, Sod-1 and EF1 $\alpha-1$ nDNA partial region), with that clustering option, all the individuals from samples no. 4 (Tyrrhenian Sea), no. 5 (Western Adriatic Sea), no. 6 (New Zealand coast) and all except one larval specimen from sample no. 3 (Alboran Sea) were assigned with high confidence level $(>90 \%)$ to $A$. pegreffi (Fig. 3). All individuals from sampling locality no. 1 (North Sea) were assigned to $A$. simplex (s. s.). Nevertheless, among the 157 Anisakis spp. individuals from sample no. 2 (Spanish-Portuguese Atlantic coast), 87 (56\%) were identified as belonging to $A$. simplex (s. s.), 60 (38\%) were assigned to $A$. pegreffi and $10(6 \%)$ were identified as individuals of mixed ancestry, having, in all cases, a $Q$-value $=0.50$ (Fig. 3). A mixed ancestry between the two taxa was also inferred for one other specimen from the Alboran Sea (sample no. 3) (Fig. 3). The 11 individuals identified as admixed by STRUCTURE were those showing a clear heterozygote patterns at all the diagnostic loci (Table 2), corresponded to the $F_{1}$ hybrid class. However, the same $11 \mathrm{~F}_{1}$ individuals showed also the heterozygote pattern when using the PCRRFLPs of rDNA (Tables 2 and 3; Fig 2c). 
Table 3. Identification of specimens belonging to the parental taxa, i.e. Anisakis pegreffi and A. simplex (s. s.), or their $\mathrm{F}_{1}$ hybrids, as inferred by STRUCTURE analysis, based on genotypes obtained from allozymes diagnostic loci and $\mathrm{E} \alpha-1 \mathrm{nDNA}$

\begin{tabular}{|c|c|c|c|c|}
\hline Sampling area & Host species & A. pegreffii & A. simplex (s. s.) & $\mathrm{F}_{1}$ hybrid \\
\hline \multicolumn{5}{|l|}{ NE Atlantic Ocean } \\
\hline \multirow[t]{3}{*}{ 1. North Sea } & Clupea harengus & _- & 8 & - \\
\hline & Micromesistius poutassou & - & 28 & - \\
\hline & Scomber scombrus & - & 68 & - \\
\hline 2. Spanish-Portuguese Atlantic coast & Merluccius merluccius & 60 & 87 & 10 \\
\hline \multicolumn{5}{|l|}{ Mediterranean Sea } \\
\hline \multirow[t]{3}{*}{ 3. Alboran Sea } & Lophius piscatorius & 9 & - & - \\
\hline & Scomber scombrus & 5 & - & - \\
\hline & Merluccius merluccius & 9 & - & 1 \\
\hline \multirow[t]{3}{*}{ 4. Tyrrhenian Sea } & Lepidopus caudatus & 23 & - & - \\
\hline & Merluccius merluccius & 29 & - & - \\
\hline & Scomber scombrus & 19 & - & - \\
\hline \multirow[t]{6}{*}{ 5. Western Adriatic Sea } & Stenella coeruleoalba & 137 & - & - \\
\hline & Engraulis encrasicolus & 3 & - & - \\
\hline & Lophius piscatorius & 5 & - & - \\
\hline & Merluccius merluccius & 18 & - & - \\
\hline & Trachurus trachurus & 26 & - & - \\
\hline & Scomber scombrus & 35 & - & - \\
\hline \multicolumn{5}{|l|}{ SW Pacific Ocean } \\
\hline 6. New Zealand coast & Globicephala melas & 109 & - & - \\
\hline
\end{tabular}

\section{DISCUSSION}

The genotyping approach based on multiple-nuclear loci not only provides a powerful means to clarifying taxonomic issues in parasitic taxa, determining their population structure, estimating gene flow and demonstrating reproductive isolation, but it also distinguishes current hybridization and introgressive hybridization phenomena. Among the nuclear codominant markers, allozymes provided valuable genetic data for distinctiveness, reproductive isolation and absence of gene flow in sympatric cryptic species of anisakid nematodes (Mattiucci and Nascetti, 2008). When sister taxa start to diverge from a common ancestor, allele frequencies at each allozyme locus are initially similar, but, over time, the genetic drift gradually results in divergence of those frequencies and, eventually, also in the appearance of new alleles in each population through mutation. Consequently, separate populations can acquire different alleles at some loci. This could be the case for those fixed allele differences found between the two Anisakis taxa at those allozyme loci (Mattiucci et al. 2014).

Similarly, at the level of sequence variation in nuclear loci, such as the EF1 $\alpha 11$ nDNA gene region, it is demonstrated here that the two taxa $A$. pegreffi and $A$. simplex (s. s.) exhibited speciesspecific fixed nucleotide variation at some positions. Those fixed difference in the EF $1 \alpha-1$ nDNA partial gene were found in a large number of specimens belonging to the two parental taxa [i.e. A. pegreffi and $A$. simplex (s. s.)] collected from both allopatry and sympatry. The large sample sizes of parental populations belonging of the two species confirm the fixation of those diagnostic positions at the partial region of the EF1 $\alpha-1 n \mathrm{DNA}$ gene. As a consequence, having validated this marker in a large number of specimens, it represents a novel nuclear marker of diagnostic value for the recognition of the two cryptic species.

Assuming that a common approach to identify hybrids is appropriate, the use of species-specific markers (fixed with alternative alleles in the parental 'taxa') requires an adequate sample size of the 'pure' parental taxa investigated; this prerequisite was fulfilled in the present study, with a large number of individuals tested from allopatric and sympatric areas for all of the fixed diagnostic loci. Secondly, one could say that geographical differences in the allele frequencies found in the parental taxa could confound the fixation of those alleles considered as alternatives of diagnostic value between the 'pure' taxa, if those 'pure parental' populations are geographically separated from the hybrid populations. The latter is not the case for the two Anisakis spp. under study, because those fixed differences at those nuclear loci (allozymes and EF1 $\alpha-1$ nDNA) were validated in both allopatric and sympatric populations, both in the present study and in previous ones (Mattiucci et al. 1997, 2014). In addition, the $\mathrm{F}_{1}$ hybrids found were observed in syntopy in both parental species in, at least, their intermediate fish hosts.

Indeed, the Bayesian clustering analysis, using nuclear allozyme loci $(A d k-2$, Pep $C-1$, Pep $C-2$ 
and Sod-1) and the EF1 $\alpha-1$ nDNA partial region, allowed us to either correctly define 'pure' individuals belonging to the two parental taxa, i.e. $A$. simplex (s. s.) or $A$. pegreffi, or to unravel patterns of natural hybridization between the two species. According to this, 10 specimens collected from the fish host in the geographical area where the two species overlap (i.e. the sympatric region of the Spanish-Portuguese Atlantic coast), and 1 individual from the Alboran Sea (considered as the Atlantic basin rather than the Mediterranean one), were found to belong to the $F_{1}$ hybrid category. These resulted from a current hybridization event between sympatric $A$. simplex (s. s.) and $A$. pegreffi. These hybrid nematodes were indeed heterozygous for all of the diagnostic allozyme loci and for the diagnostic nucleotide positions observed in the EF1 $\alpha-1 n$ DNA gene (Fig. 2). All of the $\mathrm{F}_{1}$ hybrids identified were at the larval stage; no $\mathrm{F}_{1}$ hybrid at the adult stage was found in the present study.

Our findings provide new insights on the hybridization of $A$. pegreffi and $A$. simplex (s. s.), which results in a contemporary interbreeding phenomenon between sympatric specimens of the two species. The frequency of current hybridization, so far observed, appears to be about $5 \cdot 5 \%$. In those sympatric geographical areas, it is known that the two parasite species can be often found in mixed infections in the same individual cetacean host (Mattiucci et al. 2014). Furthermore, considering that the number of mature females of these anisakids is generally higher than that of mature males in their definitive hosts (Mattiucci, personal communication), it could be that when the intensity of the infection by one of these two species is low, mating events between the two species could occur, resulting in a first generation $\left(\mathrm{F}_{1}\right)$ of larval hybrids. In the case of the $F_{1}$ hybrids identified here, 10 resulted from the mating of female $A$. simplex (s. s.) with male of $A$. pegreffii, causing a maternal inheritance of the mtDNA of $A$. simplex (s. s.), and one exhibited a $A$. pegreffi matrilineage (data obtained from the sequence analysis of the mtDNA cox 2 region; data not shown). On the other hand, it has been suggested that there is a tendency for hybridization to take place preferentially between parental species differing greatly in abundance. This hypothesis suggests that the absence of conspecific pairing partners and mating stimuli for females of rarer species may be important factors in increasing the likelihood of interspecific current hybridization (Avise and Saunders, 1984).

Larval stages of $\mathrm{F}_{1}$ hybrids between $A$. pegreffi and $A$. simplex (s. s.) have previously been recorded, respectively, from the horse mackerel, Trachurus trachurus (see Mattiucci et al. 2008) and European hake, Merluccius merluccius (see Mattiucci et al. 2004; Cipriani et al. 2015) collected in a sympatric region of Spanish Atlantic waters. However, even if these larvae reach the definitive host, the lack of other hybrid generations (backcrosses), as seen in the present study, appears to support the hypothesis that some selective factors decrease $\mathrm{F}_{1}$ hybrid fitness. Laboratory crosses might contribute to clarifying these aspects of a natural hybridization between the two taxa, as performed for other parasitic helminths (Théron et al. 1989). However, while the in vitro culture of the two species of Anisakis, from the L3 stage to their adult stage, is clearly possible (Nascetti et al. 1986), other steps in the lifecycle of these parasites, including the infection of the first intermediate hosts, have never been carried out.

Contemporary hybridization events (i.e. $\mathrm{F}_{1}$ generation) appear to be a current phenomenon happening between other cryptic species of anisakid nematodes. Indeed, $\mathrm{F}_{1}$ adult nematodes were detected by multi-loci allozyme analysis between Pseudoterranova decipiens (s. s.) and P. krabbei, often occurring in sympatry and syntopy in the same pinniped as definitive hosts from NE Atlantic waters (Paggi et al. 1991). Similarly, the occurrence of $F_{1}$ hybrids was observed between the two cryptic species, Contracaecum rudolphii sp. A and C. rudolphii sp. B from fish-eating birds (cormorant, Phalacrocorax carbo sinensis) in areas of sympatry (Mattiucci and Nascetti, unpublished results). Other cryptic species of nematodes, such as Paramacrostrongylus spp. from species of kangaroo, are able to hybridize in an area where the ranges of the two host species overlap (Chilton et al. 1997). Even in the case of highly separated taxa, such as between the two cryptic ascaridoid species of equids, Parascaris univalens and Parascaris equorum, there is some evidence that they might hybridize (Biocca et al. 1978; Bullini et al. 1978); however, they produce infertile offspring (Goday and Pimpinelli, 1986). To our knowledge, other examples of contemporary hybridization have been detected between Ascaris lumbricoides and Ascaris suum; indeed, Bayesian clustering based on microsatellite data revealed evidence for hybridization in sympatric populations from Guatemala and China (Criscione et al. 2007; Detwiler and Criscione, 2010). Similarly, in other helminth species, such as Schistosoma mansoni and S. rodhaini, the use of Bayesian clustering methods based on microsatellite datasets has demonstrated the occurrence of recent cross-transmission events between the two taxa (Steinauer et al. 2010).

In terms of ecological processes associated with parasite hybridization, different possible hosthybrid-parasite interactions can result (Fritz et al. 1999). Evidence of current hybridization between parasite taxa raises questions with regard to the epidemiology and ecological aspects of these parasites, such as a differential potential transmission of hybrids to a new host, a greater or lower adaptation 
to an intermediate host, or a potentially wider geographical range of the 'parental' taxa resulting from a greater adaptation to both biotic and abiotic factors. It has indeed been observed that some hybrids can colonize new host species, or exhibit an increased level of host infectivity and pathogenicity, exceeding those of either of the parental taxa. Furthermore, hybrid parasites have also exhibited different host susceptibility/resistance traits with respect to the parental taxa, and hybrid phenotypes of parasites have shown some changes in the epidemiological parameters, such as prevalence or density, within a geographical area or within definitive and intermediate hosts (Théron et al. 1989; Criscione et al. 2007; Volf et al. 2007; Dybdahl et al. 2008; Steinauer et al. 2008; Detwiler and Criscione, 2010).

The finding here of $\mathrm{F}_{1}$ hybrids between $A$. simplex (s. s.) and $A$. pegreffi $i$ appears to be not associated with a particular epidemiological pathway. All of the $\mathrm{F}_{1}$ larvae identified were collected from nine specimens of a demersal fish, the European hake Merluccius merluccius, caught in waters where the parasites occur in sympatry. The larvae were all found in co-infections with the two parental species, $A$. pegreffi and $A$. simplex (s. s.), except in one case. Most of the $\mathrm{F}_{1}(N=9)$ larvae were found in the visceral body cavity of the host; whereas, only in two cases they were located in the flesh of the fish. A significant difference in the site of infection has been reported for these two species in $M$. merluccius for sympatric and syntopic populations, with $A$. simplex (s. s.) having a greater capacity to invade the musculature the fish (Cipriani et al. 2015). Further research, using a larger number of correctly identified hybrid individuals, might highlight different scenarios in some phenotypic traits, such as, for instance, a differential capacity of invading host tissues, between the F1 hybrids and the parental species. In other helminths, such as a species of the digenean genus Microphallus, the infectivity of $\mathrm{F}_{1}$ hybrid parasites was lower with respect to that exhibited by the parental species (Dybdahl et al. 2008); these authors suggested that the lower fitness of the hybrids was due to outbreeding depression in the hybrids.

The present study also demonstrates that current hybridization outside the sympatric areas of the two cryptic species does not occur. Indeed, in the eastern (Adriatic Sea) and western (Tyrrhenian Sea) Mediterranean, as well as in strict allopatric areas (New Zealand coast), no $F_{1}$ hybrids were detected by the multi-loci approach. Indeed, the Bayesian clustering, based on allozymes and the EF1 $\alpha-1$ nDNA gene, clearly indicated that all the specimens of Anisakis spp. from the Mediterranean Sea, except for one individual collected from the Alboran Sea, an area of sympatry of the two Anisakis species (Mattiucci et al. 2015). On the other hand, Alboran
Sea is actually considered an Atlantic basin water rather than a Mediterranean one (Tintore et al. 1988). Similarly, those specimens collected in hosts from off the New Zealand coast (allopatric area), were assigned at a high probability level (100\%) to the species $A$. pegreffii. Similarly, all the specimens collected from the North Sea were assigned, at a high probability level $(100 \%)$, to the parental species $A$. simplex (s. s.). Conversely, if based only on the PCR-RFLP analysis of ITS rDNA, a certain number of 'hybrids' were identified in the present study from these allopatric areas mentioned above (Table 2). They were recognized at both larval and adult stages, not only in hosts from Spanish Atlantic coasts $(N=13)$ but also from various areas of the Mediterranean Sea $(N=16)$, and even in samples collected in strictly allopatric areas, i.e. New Zealand waters $(N=2)$ and the North Sea $(N=1)$. Nevertheless, Bayesian clustering demonstrated that, among those specimens, 19 were correctly assigned to one of the parental species, i.e. $A$. pegreffii or $A$. simplex (s. s.), when based on allozyme loci and the EF1 $\alpha-1$ nDNA gene (Table 2). On the other hand, the finding of numerous larval and adult hybrid specimens has previously been reported by several authors in those areas of the Mediterranean Sea (Farjallah et al. 2008; Meloni et al. 2011; Cavallero et al. 2012, 2014; Chaligiannis et al. 2012; Pekmezci et al. 2014; Molina-Fernández et al. 2015), as just inferred from analyses of the ITS region of rDNA. In the present study, if the analysis of the ITS region of the rDNA gene had been the only conventional marker used in the identification of the parasites which we identified, a misidentification of these specimens of Anisakis would have resulted. It is likely that the two nucleotide positions found in the ITS-1 of rDNA ]i.e. 278 showing $\mathrm{C}$ in $A$. pegreffi and $\mathrm{T}$ in $A$. simplex (s. s.), and 294 showing $\mathrm{C}$ in $A$. pegreffii and $\mathrm{T}$ in $A$. simplex (s. s.)] are, according to D'Amelio et al. (2000), not actually fixed diagnostic markers. As a consequence, the nucleotide position 294, detected at the PCR-RFLPs analysis by HinfI in the ITS1 rDNA, cannot be retained as a $100 \%$ diagnostic marker between the two species, as previously stated (D'Amelio et al. 2000), just because it is a shared polymorphism between the two taxa. This could be the likely the outcome of the incomplete lineage sorting of a shared ancestral variation, or the result of a historical introgression at this lone marker, resulting in a polymorphism in both $A$. pegreffii and $A$. simplex (s. s.), occurring at the I'TS-1 region of rDNA.

\section{Concluding remarks}

In retrospect, the present study has demonstrated that single molecular markers on their own based on the ITS region of rDNA were not always able 
to recognize 'pure' specimens belonging to the two cryptic taxa and, even less, successfully, their hybrid categories. On the other hand, as previously suggested for other helminth species (Criscione et al. 2007) the ITS (rDNA complex in general) is a multi-copy gene which undergoes concerted evolution phenomena; as a consequence, it lacks the power to disentangle hybridization events between closely related taxa (Ganley and Kobayashi, 2007).

However, based on the present results, the use of other nuclear markers (i.e. allozymes and the novel markers obtained from the EF1 $\alpha-1$ nDNA gene) not only permitted the clear distinction of specimens belonging to the two cryptic species $A$. simplex (s. s.) and $A$. pegreffi, but also enabled the distinguishing of current hybridization and introgressive hybridization events. Indeed, data obtained from these nuclear markers suggest that no introgressive hybridization takes places between the two species; this conclusion is supported by evidence that no backcrossing with the two parental species - which represents subsequent generations of hybrids were found in our study among the large number of sympatric and allopatric specimens examined. This finding suggests that, even if current hybridization might likely occur between $A$. pegreffi and $A$. simplex (s. s.) in some sympatric areas (i.e. the NE Atlantic waters off the Spanish-Portuguese coast and the Alboran Sea), the resulting offspring appear to have a reduced fitness. It is likely that either the $F_{1}$ offspring is infertile, even if it reaches the adult stage, or that selection disadvantages the survival of hybrid offspring, or that some reproductive isolating mechanisms do not permit backcrossing of $\mathrm{F}_{1}$ hybrids with the parental types. As a consequence, the two species maintain their identity.

On the other hand, identification of these hybridization phenomena is essential to improving our understanding of the micro-evolutionary processes which have accompanied the speciation of these parasites. It is also important in terms of elucidating anisakid ecology, including the distributional ranges and overlap of the species. It will also shed light on the life-cycles of these parasites, including any intermediate/paratenic host preferences, epidemiological parameters of infection and their pathogenicity/virulence in natural and accidental hosts, such as humans. The latter is of particular importance, since the zoonotic disease anisakiasis has been so far reported as being caused by both $A$. simplex (s. s.) and $A$. pegreffii (D'Amelio et al. 1999; Umehara et al. 2007; Mattiucci et al. 2011, 2013).

Finally, the present study takes the advantage of the use of a Bayesian clustering method to assess the identification of pure samples of parental species and samples of mixed ancestry. Such tools, provided by the STRUCTURE and NEWHYBRIDS software) are advantageous because the analyses are able to indicate both contemporary hybridization and events of past hybridization, detecting hybrid categories going back to two or three generations (Gilabert and Wasmuth, 2013). Thus, future work using highly polymorphic markers, such as microsatellites, SNPs, and model-based Bayesian clustering methods, will enable us not only to clarify other hybridization events between closely related parasite taxa, but also to provide knowledge on the ecological significance and phenotypic characteristics of hybrid parasites.

\section{SUPPLEMENTARY MATERIAL}

To view supplementary material for this article, please visit http://dx.doi.org//10.1017/S0031182016000330.

\section{ACKNOWLEDGEMENTS}

The Authors are very grateful to two anonymous referees for their constructive and insightful comments that have helped to improve this manuscript. We thank David I. Gibson for reading the manuscript.

\section{FINANCIAL SUPPORT}

SM, VA, MP, PC, AL and GN carried out the research with funding received from the 'European Union's Seventh Framework Programme for research, technological development and demonstration', under the grant agreement no. 312068 'PARASITE'.

\section{REFERENCES}

Abollo, E., Gestal, C. and Pascual, S. (2001). Anisakis infestation in marine fish and cephalopods from Galician waters: an updated perspective. Parasitology Research 87, 492-499.

Abollo, E., Paggi, L., Pascual, S. and D'Amelio, S. (2003). Occurrence of recombinant genotypes of Anisakis simplex s.s. and Anisakis pegreffi (Nematoda: Anisakidae) in an area of sympatry. Infection, Genetics and Evolution 3, 175-181.

Agatsuma, T., Arakawa, Y., Iwagami, M., Honzako, Y., Cahyaningsih, U., Kang, S. and Hong, S. (2000). Molecular evidence of natural hybridization between Fasciola hepatica and $F$. gigantica. Parasitology International 49, 231-238.

Anderson, E. C. and Thompson, E. A. (2002). A model-based method for identifying species hybrids using multilocus genetic data. Genetics 160, 1217-1229.

Anderson, T. J. C. (2001). The dangers of using single locus markers in parasite epidemiology: Ascaris as a case study. Trends in Parasitology 17, $183-188$.

Avise, J. C. and Saunders, N. C. (1984). Hybridization and introgression among species of sunfish (Lepomis): analysis by mitochondrial DNA and allozyme markers. Genetics 108, 237-255.

Avise, J. C. and Wollenberg, K. (1997). Phylogenetics and the origin of species. Proceedings of the National Academy of Science 94, 7748-7755.

Biocca, E., Nascetti, G., Iori, A., Costantini, R. and Bullini, L. (1978). Descrizione di Parascaris univalens, parassita degli equini, e suo differenziamento da Parascaris equorum. Accademia Nazionale Lincei Rendiconti Classe Scienze Fisiche Matematiche Naturali Serie 65, 133-141.

Bullini, L., Nascetti, G., Ciafrè, S., Rumore, F. and Biocca, E. (1978). Ricerche cariologiche ed elettroforetiche su Parascaris univalens e Parascaris equorum. Accademia Nazionale Lincei Rendiconti Classe Scienze Fisiche Matematiche Naturali Serie 65, 151-156.

Cavallero, S., Ligas, A., Bruschi, F. and D'Amelio, S. (2012). Molecular identification of Anisakis spp. from fishes collected in the Tyrrhenian Sea (NW Mediterranean). Veterinary Parasitology 187, $563-566$.

Cavallero, S., Costa, A., Caracappa, S., Gambetta, B. and D'Amelio, S. (2014). Putative hybrids between two Anisakis cryptic 
species: molecular genotyping using high resolution melting. Experimental Parasitology 146, 87-93.

Chaligiannis, I., Lalle, M., Pozio, E. and Sotiraki, S. (2012). Anisakidae infection in fish of the Aegean Sea. Veterinary Parasitology 184, 362-366.

Chilton, N. B., Beveridge, I., Hoste, H. and Gasser, R. B. (1997). Evidence for hybridisation between Paramacropostrongylus iugalis and $P$. typicus (Nematoda: Strongyloidea) in grey kangaroos, Macropus fuliginosus and $M$. giganteus, in a zone of sympatry in eastern Australia. International Fournal for Parasitology 27, 475-482.

Chou, Y. Y., Wang, C. S., Chen, H. G., Chen, H. Y., Chen, S. N. and Shih, H. H. (2011). Parasitism between Anisakis simplex (Nematoda: Anisakidae) third-stage larvae and the spotted mackerel Scomber australasicus with regard to the application of stock identification. Veterinary Parasitology 177, 324-331.

Cipriani, P., Smaldone, G., Acerra, V., D'Angelo, L., Anastasio, A. Bellisario, B., Palma, G., Nascetti, G. and Mattiucci, S. (2015). Genetic identification and distribution of the parasitic larvae of Anisakis pegreffii and Anisakis simplex (s. s.) in European hake Merluccius merluccius from the Tyrrhenian Sea and Spanish Atlantic coast: implications for food safety. International fournal of Food Microbiology 198, 1-8.

Criscione, C. D., Poulin, R. and Blouin, M. S. (2005). Molecular ecology of parasites: elucidating ecological and microevolutionary processes. Molecular Ecology 14, 2247-2257.

Criscione, C. D., Anderson, J. D., Sudimack, D., Peng, W., Jha, B., Williams-Blangero, S. and Anderson, T. J. C. (2007). Disentangling hybridization and host colonization in parasitic roundworms of humans and pigs. Proceedings of the Royal Society B 274, 2669-2677.

D'Amelio, S., Mathiopoulos, K.D., Brandonisio, O., Lucarelli, G., Doronzo, F. and Paggi, L. (1999). Diagnosis of a case of gastric anisakidosis by PCR-based restriction fragment length polymorphism analysis. Parassitologia 41, 591-593.

D’Amelio, S., Mathiopoulos, K. D., Santos, C.P., Pugachev, O. N., Webb, S. C., Picanço, M. and Paggi, L. (2000). Genetic markers in ribosomal DNA for the identification of members of the genus Anisakis (Nematoda: Ascaridoidea) defined by polymerase chain reaction-based restriction fragment length polymorphism. International fournal for Parasitology 30, 223-226.

Detwiler, J. T. and Criscione, C. D. (2010). An infectious topic in reticulate evolution: introgression and hybridization in animal parasites. Genes 1, 102-123.

Dunams-Morel, D. B., Reichard, M. V., Torretti, L., Zarlenga, D. S. and Rosenthal, B. M. (2012). Discernible but limited introgression has occurred where Trichinella nativa and the T6 genotype occur in sympatry. Infection Genetics and Evolution 12, 530-538.

Dybdahl, M. F., Jokela, J., Delph, L. F., Koskella, B. and Lively, C. M. (2008). Hybrid fitness in a locally adapted parasite. The American Naturalist 172, 772-782.

Elder, J. F. and Turner, B. J. (1995). Concerted evolution of repetitive DNA sequences in eukaryotes. The Quarterly Review of Biology 70, 297-320. Evanno, G., Regnaut, S. and Goudet, J. (2005). Detecting the number of clusters of individuals using the software STRUCTURE: a simulation study. Molecular Ecology 14, 2611-2620.

Farjallah, S., Slimane, B. B., Busi, M., Paggi, L., Amor, N., Blel, H., Said, K. and D'Amelio, S. (2008). Occurrence and molecular identification of Anisakis spp. from the North African coasts of Mediterranean Sea. Parasitology Research 102, 371-379.

Fritz, R. S., Moulia, C. and Newcombe, G. (1999). Resistance of hybrid plants and animals to herbivores, pathogens, and parasites. Annual Review of Ecology, Evolution, and Systematics 30, 565-591.

Ganley, A. R. D. and Kobayashi, T. (2007). Highly efficient concerted evolution in the ribosomal DNA repeats: total rDNA repeat variation revealed by whole-genome shotgun sequence data. Genome Research 17 , 184-191.

Gilabert, A. and Wasmuth, J. D. (2013). Unravelling parasitic nematode natural history using population genetics. Trends in Parasitology 29, 438-448. Goday, C. and Pimpinelli, S. (1986). Cytological analysis of chromosomes in the two species Parascaris univalens and $P$. equorum. Chromosoma 94, 1-10.

Larkin, M. A., Blackshields, G., Brown, N.P., Chenna, R., McGettigan, P.A., McWilliam, H., Valentin, F., Wallace, I. M., Wilm, A., Lopez, R., Thompson, J. D., Gibson, T. J. and Higgins, D. G. (2007). Clustal $\mathrm{W}$ and Clustal $\mathrm{X}$ version 2.0. Bioinformatics 23, 2947-2948.

Lee, M. H., Cheon, D. and Choi, C. (2009). Molecular genotyping of Anisakis species from Korean sea fish by polymerase chain reactionrestriction fragment length polymorphism (PCR-RFLP). Food Control 20, 623-626.
Levsen, A. and Karl, H. (2014). Anisakis simplex (s. l.) in grey gurnard (Eutrigla gurnardus) from the North Sea: food safety considerations in relation to fishing ground and distribution in the flesh. Food Control 36 15-19.

Levsen, A. and Lunestad, B. T. (2010). Anisakis simplex third stage larvae in Norwegian spring spawning herring (Clupea harengus L.), with emphasis on larval distribution in the flesh. Veterinary Parasitology 17, 247-253.

Martìn-Sànchez, J., Artacho-Reinoso, M. E., Dìaz-Gavilàn, M. and Valero-Lòpez, A. (2005). Structure of Anisakis simplex s. 1. populations in a region sympatric for $A$. pegreffii and $A$. simplex s.s. Absence of reproductive isolation between both species. Molecular and Biochemical Parasitology 141, 155-162.

Mattiucci, S. and Nascetti, G. (2008). Advances and trends in the molecular systematics of anisakid nematodes, with implications for their evolutionary ecology and host-parasite co-evolutionary processes. Advances in Parasitology 66, 47-148

Mattiucci, S., Nascetti, G., Cianchi, R., Paggi, L., Arduino, P., Margolis, L., Brattey, J., Webb, S. C., D'Amelio, S., Orecchia, P. and Bullini, L. (1997). Genetic and ecological data on the Anisakis simplex complex with evidence for a new species (Nematoda, Ascaridoidea, Anisakidae). Fournal of Parasitology 83, 401-416.

Mattiucci, S., Abaunza, P., Ramadori, L. and Nascetti, G. (2004). Genetic identification of Anisakis larvae in European hake from Atlantic and Mediterranean waters for stock recognition. Fournal of Fish Biology 65, 495-510.

Mattiucci, S., Cimmaruta, R., Cipriani, P., Abaunza, P. Bellisario, B. and Nascetti, G. (2015). Integrating Anisakis spp. parasites data and host genetic structure in the frame of a holistic approach for stock identification of selected Mediterranean Sea fish species. Parasitology 142, 90-108.

Mattiucci, S., Farina, V., Campbell, N., Mackenzie, K., Ramos, P., Pinto, A. L., Abaunza, P. and Nascetti, G. (2008). Anisakis spp. larvae (Nematoda: Anisakidae) from Atlantic horse mackerel: their genetic identification and use as biological tags for host stock identification. Fisheries Research 89, 146-171.

Mattiucci, S., Paoletti, M., Borrini, F., Palumbo, M., Palmieri, R. M., Gomes, V., Casati, A. and Nascetti, G. (2011). First molecular identification of the zoonotic parasite Anisakis pegreffi (Nematoda: Anisakidae) in a paraffin-embedded granuloma taken from a case of human intestinal anisakiasis in Italy. BMC Infectious Diseases 11, 82.

Mattiucci, S., Fazii, P., De Rosa, A., Paoletti, M., Salomone Megna, A., Glielmo, A., De Angelis, M., Costa, A., Meucci, C., Calvaruso, V., Sorrentini, I., Palma, G., Bruschi, F. and Nascetti, G. (2013). Anisakiasis and Gastroallergic reactions associated with Anisakis pegreffi infection, Italy. Emerging Infectious Diseases 19, 496-499.

Mattiucci, S., Cipriani, P., Webb, S.C., Paoletti, M., Marcer, F., Bellisario, B., Gibson, D. I. and Nascetti, G. (2014). Genetic and morphological approaches distinguish the three sibling species of the Anisakis simplex species complex, with a species designation as Anisakis berlandi n. sp. for A. simplex sp. C (Nematoda: Anisakidae). Fournal of Parasitology 100, 199-214.

Mayr, E. and Ashlock, P. D. (1969). Principles of Systematic Zoology. McGraw-Hill, New York, 145-166.

Meloni, M., Angelucci, G., Merella, P., Siddi, R., Deiana, C., Orrù, G. and Salati, F. (2011). Molecular characterization of Anisakis larvae from fish caught off Sardinia. Fournal of Parasitology 97, 908-914.

Molina-Fernández, D., Malagón, D., Gómez-Mateos, M. Benítez, R., Martín-Sánchez, J., and Adroher, F. J. (2015). Fishing area and fish size as risk factors of Anisakis infection in sardines (Sardina pilchardus) from Iberian waters, southwestern Europe. International Fournal of Food Microbiology 203, 27-34.

Nadler, S. A. and Pérez-Ponce De León, G. (2011). Integrating molecular and morphological approaches for characterizing parasite cryptic species: implications for parasitology. Parasitology 138, 1688-1709.

Nascetti, G., Paggi, L., Orecchia, P., Smith, J. W., Mattiucci, S. and Bullini, L. (1986). Electrophoretic studies on the Anisakis simplex complex (Ascaridida: Anisakidae) from the Mediterranean and North-East Atlantic. International Fournal for Parasitology 16, 633-640.

Okamoto, M., Nakao, M., Blair, D., Anantaphruti, M. T., Waikagul, J. and Ito, A. (2010). Evidence of hybridization between Taenia saginata and Taenia asiatica. Parasitology International 59, 70-74. Paggi, L., Nascetti, G., Cianchi, R., Orecchia, P., Mattiucci, S., D'Amelio, S., Berland, B., Brattey, J., Smith, J. W. and Bullini, L. (1991). Genetic evidence for three species within Pseudoterranova decipiens (Nematoda, Ascaridida, Ascaridoidea) in the North Atlantic and Norwegian and Barents Seas. International Fournal for Parasitology 21, 195-212. 
Pekmezci, G. Z., Onuk, E. E., Bolukbas, C.S., Yardimci, B., Gurler, A. T., Acici, M. and Umur, S. (2014). Molecular identification of Anisakis species (Nematoda: Anisakidae) from marine fishes collected in Turkish waters. Veterinary Parasitology 201, 82-94.

Pérez-Ponce de León, G., and Nadler, S. A. (2010). What we don't recognize can hurt us: a plea for awareness about cryptic species. Fournal of Parasitology 96, 453-464.

Pontes, T., D'Amelio, S., Costa, G. and Paggi, L. (2005). Molecular characterization of larval anisakid nematodes from marine fishes of Madeira by a PCR-based approach, with evidence for a new species. Fournal of Parasitology 91, 1430-1434.

Pritchard, J. K., Stephens, M. and Donnelly, P. (2000). Inference of population structure using multilocus genotype data. Genetics 155 , 945-959. Quiazon, K. M., Yoshinaga, T. and Ogawa, K. (2011). Distribution of Anisakis species larvae from fishes of the Japanese waters. Parasitology International 60, 223-226.

Rice, W. R. (1989). Analyzing tables of statistical tests. Evolution 43, $223-$ 225.

Rousset, F. (2008). GENEPOP'007: a complete re-implementation of the GENEPOP software for Windows and Linux. Molecular Ecology Resources 8, 103-106.

Steinauer, M. L., Hanelt, B., Mwangi, I. N., Maina, G. M., Agola, L. E., Kinuthia, J. M., Mutuku, M.W., Mungai, B. N., Wilson, W. D., Mkoji, G. M. and Loker, E. S. (2008). Introgressive hybridization of human and rodent schistosome parasites in western Kenya. Molecular Ecology 17, 5062-5074.

Steinauer, M. L., Blouin, M. S. and Criscione, C. D. (2010). Applying evolutionary genetics to schistosome epidemiology. Infection, Genetics and Evolution 10, 433-443.
Suzuki, J., Murata, R., Hosaka, M. and Araki, J. (2010). Risk factors for human Anisakis infection and association between the geographic origins of Scomber japonicus and anisakid nematodes. International fournal of Food Microbiology 137, 88-93.

Théron, A. (1989). Hybrids between Schistosoma mansoni and S. rodhaini: characterization by cercarial emergence rhythms. Parasitology 99, 225-228. Tintore, J., La Violette, P. E., Blade, I. and Cruzado, G. (1988). A study of intense density front in the eastern Alboran Sea: the Almeria-Oran front. Fournal of Physical Oceanography 18, 1384-1397.

Umehara, A., Kawakami, Y., Matsui, T., Araki, J. and Uchida, A. (2006). Molecular identification of Anisakis simplex sensu stricto and Anisakis pegreffii (Nematoda: Anisakidae) from fish and cetaceans in Japanese waters. Parasitology International 55, 267-271.

Umehara, A., Kawakami, Y., Araki, J. and Uchida, A. (2007) Molecular identification of the etiological agent of the human anisakiasis in Japan. Parasitology International 56, 211-215.

Valentini, A., Mattiucci, S., Bondanelli, P., Webb, S. C., MignucciGiannone, A., Colon-Llavina, M. M. and Nascetti, G. (2006) Genetic relationships among Anisakis species (Nematoda: Anisakidae) inferred from mitochondrial cox 2 sequences and comparison with allozyme data. Fournal of Parasitology 92, 156-166.

Volf, P., Benkova, I., Myskova, J., Sadlova, J., Campino, L. and Rave1, C. (2007). Increased transmission potential of Leishmania major/ Leishmania infantum hybrids. International Fournal for Parasitology 37, 589-593.

Zhu, X. Q., D'Amelio, S., Paggi, L. and Gasser, R. B. (2000). Assessing sequence variation in the internal transcribed spacer of ribosomal DNA within and among members of the Contracaecum osculatum complex (Nematoda: Ascaridoidea: Anisakidae). Parasitology Research 86, 677-683. 